\title{
Measuring Comprehensiveness of Primary Care: Challenges and Opportunities
}

\author{
Ann S. O'Malley, MD, MPH and Eugene C. Rich, MD
}

Mathematica Policy Research, Washington, DC, USA.

Comprehensiveness of primary care (the extent to which the clinician, as part of the primary care team, recognizes and meets the majority of each patient's physical and mental health care needs) is an important element of primary care, but seems to be declining in the U.S. This is concerning, because more comprehensive primary care is associated with greater equity and efficiency in health care, improved continuity, less care fragmentation and better health outcomes. Without measurement and support for its improvement, comprehensiveness may further decline as other measured aspects of primary care (e.g. access, coordination) improve. To track, support and improve comprehensiveness, it is useful to have valid and reliable ways to measure it. This paper discusses challenges to measuring comprehensiveness for a primary care team's patient panel, presents survey and claimsbased measures of comprehensiveness, and provides suggestions for future research.

KEY WORDS: Primary health care; Health services research; Comprehensive; Comprehensiveness; Quality of care; Patient outcomes; Chronic conditions.

J Gen Intern Med 30(Suppl 3):S568-75

DOI: $10.1007 / \mathrm{s} 11606-015-3300-\mathrm{Z}$

(C) Society of General Internal Medicine 2015

\section{INTRODUCTION}

A key element of primary care, "comprehensiveness" is the extent to which the primary care clinician, as part of the primary care team, recognizes and meets the majority of each patient's physical and common mental health care needs, including prevention and wellness, and acute, chronic and comorbid condition management. ${ }^{1,2}$ Comprehensiveness includes both the scope of services offered and the depth and breadth of conditions managed by the primary care team, based in part on the prevalence of health concerns and conditions in the population served. Comprehensiveness, along with accessibility, continuity, coordination and accountability for the whole person, differentiates primary care from other forms of care (e.g. specialty care, hospital care) ${ }^{1-5}$

Comprehensiveness is associated with numerous benefits, ${ }^{1,5-12}$ yet several studies suggest it is declining in the U.S. and Canada ${ }^{13-17}$ Here, we discuss the rationale for measuring comprehensiveness in primary care, enumerate the challenges, including available data sources, then describe approaches to measuring comprehensiveness and suggest areas for future research.

Published online June 24, 2015

\section{Why Measure Comprehensiveness of Primary Care?}

Comprehensiveness, measured primarily by survey and administrative data, is associated with better outcomes for patients and populations. Greater efficiency, defined as a wider range of services, with better health outcomes, provided at lower costs, ${ }^{5-10}$ lower hospitalization rates for ambulatory care-sensitive conditions, ${ }^{8,11}$ improved health and better selfreported health outcomes, ${ }^{6,8,9,11,12}$ and greater equity (i.e., reduced disparities in disease severity as a result of earlier detection and prevention across different populations), ${ }^{5-10}$ are all linked to more comprehensive primary care. Without comprehensive primary care, patients experience fragmented care across numerous different specialists, resulting in higher healthcare costs, more diagnostic tests and interventions, and more types of medications. ${ }^{1,8,18}$

The decline in comprehensiveness of primary care is not an inevitable aspect of modern health care. In the Netherlands, for example, comprehensiveness appears to be increasing. ${ }^{19}$ In fact, many countries lead the U.S. in comprehensive primary care. ${ }^{1,20}$ The U.S. decline may be due to numerous factors, including the dramatic growth in the number of specialists, health plans that enable direct access to specialty care for common conditions, specialist-oriented medical centers, and insufficient support of and payment for practices to comprehensively manage the expanding population of patients with comorbidities. ${ }^{1,21-32}$

In addition, patient-centered medical home (PCMH) $)^{33,34}$ standards include other primary care features, such as accessibility and coordination, ${ }^{35-38}$ but underemphasize comprehensiveness. ${ }^{39,40}$ Some include a one-time health risk assessment and reminders about individual services for "individual conditions." Although some PCMH recognition tools include care management plans that begin to address the notion of comprehensiveness, they seldom highlight the scope of services offered and the extent to which conditions and comorbidities are managed by the primary care practice. While standards are increasingly emphasizing the important element of care coordination, primary care practices may be tracking specialist referrals for every problem patients have (including common primary care problems) without managing any of these problems directly.

Primary care providers may need more resources to deliver comprehensive care, and without measurement and support for its improvement, comprehensiveness may further whither as other measured aspects of primary care improve. 


\section{General Challenges to Measuring Comprehensiveness}

The under-measurement of comprehensiveness results from several factors, including the lack of a common vocabulary, patient population differences, insufficient agreement across specialties, and inadequate data sources.

Lack of Common Vocabulary. Some studies have measured comprehensiveness by the "scope" or "range of services." For this paper, "scope of services" means the types of services a primary care practice provides (e.g., nutrition counseling, family planning, minor laceration repair, etc.). However, we also emphasize a factor that has received even less attention: the depth and breadth of conditions and problems the primary care clinician and team manage. This includes not only preventive care and acute, chronic and multi-morbid conditions, but also the range of problems and conditions within these areas that a generalist manages without immediate referral to a specialist. ${ }^{1,5}$

Needs of Population Served. Common comprehensiveness definitions focus on meeting the large majority of patients' needs, meaning "a range of services broad enough to care for all health needs except those too uncommon to maintain competence. ${ }^{\eta 1,2,4}$ Population needs determine the depth and breadth of conditions and scope of services a practice should provide. If demand for particular services is insufficient for a practice to maintain the necessary skills and equipment, referral elsewhere may be needed.

Training May Not Equal Practice. Practicing clinicians with primary care training do not necessarily provide comprehensive care. Despite receiving training in obstetrics, many family physicians do not provide obstetrical care, ${ }^{42}$ and some internists trained in primary care competencies practice inpatient care exclusively ${ }^{31,32}$ or in other narrow venues of care. ${ }^{43,44}$

\section{Lack of Professional Agreement on Respective Roles} and Indications for Referral. Comprehensive primary care providers make fewer referrals to specialists. ${ }^{1}$ The range of practitioner types in a practice and their combined skill sets affect the patient needs the practice can meet. ${ }^{29}$ Despite efforts to outline the problems that are most common in primary care $\mathrm{c}^{1,41,45,46}$ and to study referrals, ${ }^{22,47,48}$ disagreement remains on when referrals are appropriate. ${ }^{49,50}$ The limited number of metrics on referrals further complicates measures of comprehensiveness. ${ }^{22}$

Inadequate Data Sources. Different data sources capture different aspects of comprehensiveness. ${ }^{51}$ Claims and surveys can provide some information on what services have been provided, but like electronic health record (EHR) data, they have limitations. Various types of data currently available for measuring comprehensiveness have relative advantages and disadvantages.

\section{Survey-Based Measures of Comprehensiveness}

Patient, provider and practice surveys have measured different aspects of comprehensiveness and have provided varying perspectives.

Leading patient surveys with items on comprehensiveness include the Primary Care Assessment Tool (PCAT), ${ }^{52}$ the Primary Care Assessment Survey (PCAS), ${ }^{53}$ and the Ambulatory Care Experiences Survey (ACES). ${ }^{54}$ The adult and core Consumer Assessment of Healthcare Providers and Systems (CAHPS)-PCMH surveys, which are commonly used to evaluate patient experiences in $\mathrm{PCMH}$ demonstrations, include items on some aspects of comprehensiveness, (e.g., whether the clinician pays attention to patients' mental and emotional health and whether preventive, acute and chronic care is provided). ${ }^{55}$ None of these, however, collect information on the breadth and depth of conditions managed.

Most provider surveys that touch on comprehensiveness focus on the scope of services provided. The PCAT ${ }^{52}$ has both physician and facility versions that ask whether the practice provides nutrition counseling, immunizations, family planning, behavioral health counseling and minor laceration repairs. The Medical Home Implementation Quotient (MHIQ) ${ }^{56}$ asks about the scope of procedures and whether the practice provides acute, chronic and prevention services and end-of-life care. While questions address such practice functions as identifying patient medication barriers and monitoring progress on outcomes, the MHIQ does not probe specific patient conditions, and provides less insight into the breadth and depth of managing specific problems or a range of conditions. Other national physician and practice surveys $\mathrm{s}^{57,58}$ have robust items on practice supports for selected chronic conditions, but do not ask specifically about the aspects of comprehensiveness that are the focus of this paper.

The Quality and Costs of Primary Care in Europe (QUALICOPC) project, which extends beyond Europe but does not include the U.S., analyzes and compares primary care in 35 countries. ${ }^{59}$ This ongoing effort includes numerous surveys, including one of primary care physicians ("GPs") that covers comprehensiveness. ${ }^{59}$ After a review of existing instruments, the QUALICOPC study measured aspects of comprehensiveness in its physician questionnaire, including available equipment and the GPs' task profiles (e.g., range of problems for which the GP is the first point of contact). The survey thus resulted in some conceptual overlap between the concepts of first-contact accessibility ${ }^{3}$ and comprehensiveness.

A new measure, developed but not yet validated, for the Agency for Healthcare Research and Quality's (AHRQ) nationally representative physician survey pilot ${ }^{60}$ asks about five common symptoms and chronic conditions (new-onset low back pain, amenorrhea, depression, sore throat, and diabetes). For each of these, both primary care and specialist physicians are asked about the extent to which the physician/practice (1) conducts the history and physical exam for the initial assessment, (2) orders and interprets the necessary diagnostic tests, (3) initiates treatment, and/or (4) refers the patient to a different 
health professional. These new items address depth of management for specific conditions, enabling comparisons on comprehensiveness among different specialties.

\section{Advantages and Limitations of Survey Measures of Comprehensiveness}

Clinician surveys on scope of services enable clinicians to report on services provided by practices, whereas claims data reflect only services billed under a specific plan benefit. Clinicians' reports on their degree of management of conditions, however, may be more subject to social desirability bias (over-reporting of the extent to which they provide comprehensive care) than items on the types of procedures a practice offers. Table 1 compares various forms of data collection on comprehensiveness of care.

While patient surveys are useful for determining whether patients feel that their needs have been met, they do have limitations. Patients may give clinicians high ratings on comprehensiveness, as they do with factors such as satisfaction and trust, in part because the clinician does things the patient values or because they have a long-standing relationship. ${ }^{61,62}$ Patient ratings may also be influenced by their beliefs about the relative merits of primary care physicians vs. specialists and by the prevailing views in their community, ${ }^{63,64}$ rather than whether the clinician is providing the professionally appropriate level of comprehensiveness. ${ }^{65}$ Additional modes of data collection to capture other aspects of comprehensiveness are likely needed. ${ }^{65}$

\section{Claims-Based Measures of Comprehensiveness}

Some studies have measured comprehensiveness across physician specialties using Medicare claims and visit abstraction data from the National Ambulatory Care Medical Survey (NAMCS). ${ }^{41,45,46,66-70}$ Several potential claims-based approaches may be useful for estimating a practice's comprehensiveness.

a. Range of conditions treated:

Investigators at the Robert Graham Center have proposed an approach based on the theory that clinicians who treat a larger number of conditions provide more comprehensive care. This method entails analyzing the number of conditions listed for evaluation and management (E\&M) visits, as identified by the International Classification of Diseases, Ninth Revision, Clinical Modification ("ICD-9-CM") codes. ${ }^{71}$ Because claims may list co-conditions that physicians are not necessarily treating, the Graham Center measure utilizes a ranked frequency distribution of all conditions treated over the course of a year by each physician. It then tallies the number of ICD-9-CM codes that account for the distribution below a given threshold value (e.g., $80 \%$ of ICD-9 codes). Flatter distributions indicate more comprehensive care, while those skewed to the left indicate less comprehensive care. For example, the group determined that $91 \%$ of family physicians billed for 12 or more ICD-9-CM codes for $80 \%$ of their practice. Using this method, $85 \%$ of internists and $95 \%$ of geriatricians would be deemed to be providing comprehensive care. ${ }^{72}$ Developed for broad comparisons of different types of physicians in different regions, this approach is being tested for use in comparing the relative comprehensiveness of individual physicians.

Rosenblatt et al. used an alternative approach in which 120 separate "diagnostic clusters" were identified in order to capture the range of conditions listed on claims. ${ }^{41,45,69}$ Diagnostic clusters group individual diagnostic codes to bring together

Table 1 Quality Comparison of Survey- vs. Claims- vs. Chart-Based Measures of Comprehensiveness of Care

\begin{tabular}{|c|c|c|c|c|c|}
\hline & $\begin{array}{l}\text { Patient } \\
\text { survey }\end{array}$ & $\begin{array}{l}\text { Physician } \\
\text { survey }\end{array}$ & $\begin{array}{l}\text { Practice } \\
\text { survey }\end{array}$ & Claims & $\begin{array}{l}\text { EHR or chart } \\
\text { review* }\end{array}$ \\
\hline $\begin{array}{l}\text { Feasibility and ease } \\
\text { of data collection }\end{array}$ & Medium & Medium & Medium & High & $\begin{array}{l}\text { Low at present but } \\
\text { could be high in } \\
\text { future once more } \\
\text { clinically meaningful } \\
\text { interoperable EHRs } \\
\text { are in place }\end{array}$ \\
\hline $\begin{array}{l}\text { Ability to capture } \\
\text { clinical appropriateness } \\
\text { of care delivered }\end{array}$ & Low & Low & Low & $\begin{array}{l}\text { Low because } \\
\text { lack clinical } \\
\text { data }\end{array}$ & Medium \\
\hline $\begin{array}{l}\text { Validity of measure } \\
\text { of scope of services }\end{array}$ & Medium & High & High & Medium & Medium \\
\hline $\begin{array}{l}\text { Validity of } \\
\text { comprehensiveness } \\
\text { measure }\end{array}$ & $\begin{array}{l}\text { High if goal is to } \\
\text { capture meeting } \\
\text { patient needs; low } \\
\text { if patient expectations } \\
\text { are that they see a } \\
\text { different specialist for } \\
\text { each body system }\end{array}$ & $\begin{array}{l}\text { High if goal is to } \\
\text { capture conditions } \\
\text { clinician sees; } \\
\text { Medium if goal is } \\
\text { to assess the depth } \\
\text { of management by } \\
\text { that clinician; } \\
\text { Low if attempting } \\
\text { to estimate meeting } \\
\text { of patient needs }\end{array}$ & $\begin{array}{l}\text { Medium as practice } \\
\text { respondent (as opposed } \\
\text { to individual clinician } \\
\text { respondent) may be } \\
\text { less aware of individual } \\
\text { clinicians' relative skills } \\
\text { and knowledge }\end{array}$ & $\begin{array}{l}\text { Unclear, } \\
\text { need to be } \\
\text { validated }\end{array}$ & $\begin{array}{l}\text { Low at present but } \\
\text { could be higher in } \\
\text { future once } \\
\text { interoperable EHRs } \\
\text { are in place }\end{array}$ \\
\hline
\end{tabular}

*Assumes one has access not just to primary care EHR/chart but also to charts of all clinicians the patient sees 
conditions with similar pathophysiologic characteristics that tend to be treated in similar ways. They simplify the ICD system to manageable proportions and compensate for idiosyncratic labeling and coding by individual physicians. ${ }^{45}$ The top 20 clusters were found to represent more than $50 \%$ of all non-referred visits to physicians, and captured the most common ambulatory conditions for which people sought care. The three primary care specialties (family medicine, internal medicine, and pediatrics) deal with the broadest range of diagnostic clusters. Other specialists, including the areas of obstetricsgynecology, cardiology, and oncology, typically treat one to three major diagnostic clusters. ${ }^{41}$

Bindman and Forrest used the expanded diagnostic clusters from the Johns Hopkins University ACG case-mix system ${ }^{73}$ to describe the comprehensiveness of primary care in an international comparison of data abstracted from office visits. ${ }^{20}$

These approaches cannot capture whether the physician has actually treated all of the conditions designated by the ICD codes on claims, and physicians may fail to identify some important health conditions (e.g., depression) during the primary care encounter. Thus there are limitations to measures based on the range of conditions documented by the primary care provider.

b. Involvement in patient conditions:

An alternative approach estimates the degree to which the primary care practice provides services within the constellation of care that the patient receives. The assumption is that when patients receive more services from specialists, the primary care physician is providing less comprehensive care.

To assess "involvement in patient conditions," one could identify all conditions (ICD codes) in each patient's E\&M claims for all physicians using claims for Medicare fee-forservice beneficiaries over a 1 -year period. Determining the percentage of various conditions managed by each clinician for a beneficiary and ordering clinicians based on who saw the greatest number of different conditions would identify the top clinician as the "comprehensive clinician" for that beneficiary. Clinician scores could be assigned based on the ratio of the number of beneficiaries for whom they were the comprehensive clinician to the total number of beneficiaries they saw.

\section{c. New problems managed:}

A comprehensive primary care practice should be able to manage most new problems that patients might experience. ${ }^{1}$ In this context, another approach estimates the extent to which a clinician manages vs. refers patients with new problems commonly seen in primary care. Primary care clinician encounters for new issues could be identified by examining a defined "look-back period" (e.g., 3 years) to ascertain that the problem (ICD code) was not previously listed for a patient. Looking forward from the index claim for that new problem in order to see who billed for it would indicate who managed it. One would then calculate the percentage of total E\&M visits associated with the new problem as provided by the clinician (numerator) vs. by all clinicians (denominator).

\section{d. Scope of services provided:}

Claims data can also be used to assess the scope of services a primary care practice delivers. Chan et al. (2002) reviewed the settings in which services were provided (e.g., outpatient, inpatient, ED, etc.) using FFS claims from practices in Ontario as a comprehensiveness indicator. ${ }^{13}$ The Robert Graham Center is also using subsets of Berenson-Eggers Type of Service (BETOS) codes) ${ }^{74}$ to count the different types of services, procedures and locations of care (e.g. office, hospital, home, ER) for which clinicians bill. ${ }^{72}$

Combinations of claims-based measures could be complementary to ensure that both scope of services and the breadth and depth of conditions managed are captured.

\section{Advantages and Disadvantages of Claims-Based Methods:}

Advantages to using claims data include their availability, relatively low cost, and, for Medicare data, their national scope. Claims include both clinical and procedural codes and site of care (outpatient, inpatient, ED, etc.), are consistent across settings, and may capture the breadth and depth of conditions recognized and treated by a practice better than surveys. Claims also include services patients have received outside their usual provider's or health system's EHR, something the current lack of interoperability makes challenging to gather with EHR data across providers.

Disadvantages to using claims are numerous, and the extent to which different approaches are subject to them varies. Tables 2, 3, and 4 compare the four main claims-based measures described above. One challenge is identifying the degree to which the clinician is truly managing conditions $\mathrm{s} /$ he lists on a claim. Clinicians or their practice may be assuming responsibility only for some of the multiple conditions reflected by ICD codes on a patient's claim. This may be inadvertently exacerbated by current risk adjustment documentation requirements to maximize reimbursement. ${ }^{75,76}$ Because traditional Medicare claims do not require the identity of the referring provider or whether specialist visits were due to referrals, it can be difficult to tell whether a primary care clinician managed a condition or simply recognized and documented a problem and then referred the patient to a specialist ("document and refer").

Systematic differences in coding behaviors among provider organizations or local markets might also skew claims-based measures of comprehensiveness. For example, research suggests regional market variation in health services use, ${ }^{63,64,77}$ and in markets with high use of services, patients may have more ICD codes identified. Thus, clinicians in some markets might appear more comprehensive when they are just collectively doing more for patients.

A related problem is the lack of sufficient clinical information in claims data to assess the clinical appropriateness of services delivered. There are a few exceptions to this, e.g., management of low back pain, for which guideline-based claims algorithms exist. ${ }^{78}$ 
Table 2 Comparison of Relevance and Feasibility of Claims-Based Measures of Comprehensiveness of Care

\begin{tabular}{|c|c|c|c|c|}
\hline & $\begin{array}{l}\text { Range of conditions } \\
\text { treated }^{\mathrm{a}}\end{array}$ & $\begin{array}{l}\text { New problems } \\
\text { managed }^{\mathbf{b}}\end{array}$ & $\begin{array}{l}\text { Involvement in } \\
\text { patient conditions }\end{array}$ & $\begin{array}{l}\text { Scope of services } \\
\text { provided }^{\mathrm{d}}\end{array}$ \\
\hline $\begin{array}{l}\text { Ability of measure to overcome risk that "document } \\
\text { and refer" behaviors will obscure measurement }\end{array}$ & Low & Medium & Low & High \\
\hline $\begin{array}{l}\text { Ability of measure to determine the clinical } \\
\text { appropriateness of services }\end{array}$ & Low & Low & Low & Low \\
\hline Complexity of calculating the measure & Medium & High & High & Low \\
\hline
\end{tabular}

${ }^{a}$ Range of conditions treated method assesses the range of ICD codes listed on claims by physicians for a given time period, e.g., 1 year.

${ }^{b} N e w$ problems managed refers to the extent to which a patient's new problem is cared for by the PCP vs. referred to another specialist.

'Involvement in patient conditions refers to the clinician's involvement in the care of a patient's conditions relative to other physicians caring for that patient.

${ }^{d}$ Scope of services refers to procedures and interventions performed at the practice, including sites of care (inpatient, outpatient, home visits, etc.)

Given that $75 \%$ of Medicare beneficiaries are in the fee-forservice program and are not required to identify a primary care provider, we focused the above discussion on claims-based methods that would not first require attribution of beneficiaries to a usual clinician. Such attribution algorithms ${ }^{79}$ might create circularity if the same claims were also used to assess comprehensiveness. Additional measures might be available, however, in health plans or systems where patients have an identified primary care provider. For example, after adjusting for case mix, primary care providers whose patients had a higher proportion of specialist visits in a given time period could be designated as less comprehensive.

\section{Directions for Future Research on Measuring Comprehensiveness of Care}

Identification of Population-Based Health Needs. To determine whether a practice meets the majority of its patients' health needs, ideally, one would first identify those needs (ranging from preventive to comorbid) and the services required to address them. This would optimally include data that is not subject to current fee-for-service payment incentives, as current claims fail to capture the full extent of population health needs (e.g., people without access to care or care for unreimbursed services.) A future gold standard for what comprehensive primary care would entail could be developed once a population's needs are identified. Pairing epidemiologic research on population health needs with concurrent measures of provider comprehensiveness could advance discussions on where practices fall short, or do well, in meeting patient needs.

How do we Validate a Measure when there is no Gold Standard? In the absence of a "gold standard" against which to assess concurrent validity of comprehensiveness metrics, an examination of relative characteristics of different measures could help determine their criterion and predictive validity. For example, a comparison of claims-based measures to either (1) survey and EHR measures of comprehensiveness for the same individuals, or (2) important patient outcomes, including quality measures, hospitalizations, efficiency and costs, could be informative.

Another approach to validating comprehensiveness measures might compare competency standards of certification

Table 3 Likelihood that Various Measurement Approaches Capture Various Aspects of Comprehensiveness

\begin{tabular}{|c|c|c|c|c|}
\hline & $\begin{array}{l}\text { Range of } \\
\text { conditions }_{\text {treated }^{\mathrm{a}}}\end{array}$ & $\begin{array}{l}\text { New problems } \\
\text { managed }^{b}\end{array}$ & $\begin{array}{l}\text { Involvement in } \\
\text { patient conditions }\end{array}$ & $\begin{array}{l}\text { Scope of services } \\
\text { provided }^{\mathrm{d}}\end{array}$ \\
\hline $\begin{array}{l}\text { Range of services (including procedures) provided in practice } \\
\text { (structural element) }{ }^{47}\end{array}$ & Low & Low & Low & High \\
\hline $\begin{array}{l}\text { Recognition of patient needs } \\
\text { (process element) }\end{array}$ & Low & Low & Medium & Low \\
\hline $\begin{array}{l}\text { Practice/PC team meets large majority of patients' healthcare } \\
\text { needs without excessive referrals (relative to other practices) }\end{array}$ & Low & Medium & Low & Low \\
\hline Breadth of conditions managed & High & Low & High & Low \\
\hline Depth of condition managed & Medium & Medium & Medium & Low \\
\hline Multimorbidity management & Low & Low & Low & Low \\
\hline
\end{tabular}

${ }^{a}$ Range of conditions treated method assesses the range of ICD codes listed on claims by physician for a given time period, e.g., 1 year.

${ }^{b}$ New problems managed refers to the extent to which a patient's new problem is cared for by the PCP vs. referred to another specialist.

${ }^{c}$ Involvement in patient conditions refers to the clinician's involvement in the care of a patient's conditions relative to other physicians caring for that patient.

${ }^{d}$ Scope of services refers to procedures and interventions performed at the practice, including sites of care (inpatient, outpatient, home visits, etc.). 
Table 4 How Claims-Based Comprehensiveness Measures would Differ for Different Clinician Types

\begin{tabular}{|c|c|c|c|c|}
\hline & $\begin{array}{l}\text { Range of conditions } \\
\text { treated }^{\mathrm{a}}\end{array}$ & $\begin{array}{l}\text { New problems } \\
\text { managed }^{b}\end{array}$ & $\begin{array}{l}\text { Involvement in patient } \\
\text { conditions } \mathrm{c}^{\mathrm{c}}\end{array}$ & $\begin{array}{l}\text { Scope of services } \\
\text { provided }^{d}\end{array}$ \\
\hline $\begin{array}{l}\text { Truly comprehensive } \\
\text { clinician providing primary } \\
\text { care to young adults: well, } \\
\text { preventive, acute, chronic } \\
\text { and multimorbid care } \\
\text { including range of } \\
\text { procedures }\end{array}$ & $\begin{array}{l}\text { Clinician would be labeled } \\
\text { as comprehensive, } \\
\text { assuming his/her panel is } \\
\text { not limited to a unique } \\
\text { population with just a few } \\
\text { needs }\end{array}$ & $\begin{array}{l}\text { Would not be able to } \\
\text { detect this, but that is } \\
\text { not the goal of this } \\
\text { measure }\end{array}$ & $\begin{array}{l}\text { Clinician would be } \\
\text { labeled as comprehensive, } \\
\text { assuming his/her panel is } \\
\text { not limited to a unique } \\
\text { population with just a few } \\
\text { needs }\end{array}$ & $\begin{array}{l}\text { Would not discriminate } \\
\text { well except for } \\
\text { procedures and site of } \\
\text { care }\end{array}$ \\
\hline $\begin{array}{l}\text { Truly comprehensive } \\
\text { clinician providing primary } \\
\text { care for geriatric } \\
\text { population: well, } \\
\text { preventive, } \\
\text { acute, chronic and } \\
\text { multimorbid care including } \\
\text { range of procedures }\end{array}$ & $\begin{array}{l}\text { Clinician would be labeled } \\
\text { as comprehensive, } \\
\text { assuming his/her panel is } \\
\text { not limited to a unique } \\
\text { population with just a few } \\
\text { needs }\end{array}$ & $\begin{array}{l}\text { Would not be able to } \\
\text { detect this, but that is } \\
\text { not the goal of this } \\
\text { measure }\end{array}$ & $\begin{array}{l}\text { Clinician would be labeled } \\
\text { as comprehensive, } \\
\text { assuming his/her panel is } \\
\text { not limited to a unique } \\
\text { population with just a few } \\
\text { needs }\end{array}$ & $\begin{array}{l}\text { Could be useful to } \\
\text { capture those doing } \\
\text { home visits, inpatient } \\
\text { care for frail elderly } \\
\text { population }\end{array}$ \\
\hline $\begin{array}{l}\text { Clinician who focuses mostly } \\
\text { on providing relevant } \\
\text { services for the conditions } \\
\text { within the purview of his/ } \\
\text { her specialty (e.g., general } \\
\text { internist vs. cardiologist) }\end{array}$ & $\begin{array}{l}\text { Would appear less } \\
\text { comprehensive, which } \\
\text { is appropriate }\end{array}$ & $\begin{array}{l}\text { How comprehensive } \\
\text { the physician appears } \\
\text { would depend on } \\
\text { whether conditions } \\
\text { were limited to those } \\
\text { most commonly seen } \\
\text { in primary care }\end{array}$ & $\begin{array}{l}\text { Would appear to be less } \\
\text { comprehensive, which is } \\
\text { appropriate }\end{array}$ & $\begin{array}{l}\text { Clinician would look } \\
\text { more comprehensive }\end{array}$ \\
\hline $\begin{array}{l}\text { Clinician working in an } \\
\text { urgent care clinic }\end{array}$ & $\begin{array}{l}\text { Could appear more } \\
\text { comprehensive than } \\
\text { actually is }\end{array}$ & $\begin{array}{l}\text { Measure not appropriate } \\
\text { for this setting }\end{array}$ & $\begin{array}{l}\text { Would appear not to be } \\
\text { comprehensive, which is } \\
\text { appropriate }\end{array}$ & $\begin{array}{l}\text { Depends on range of } \\
\text { procedures offered in } \\
\text { the urgent care clinic }\end{array}$ \\
\hline $\begin{array}{l}\text { Clinician who tends to } \\
\text { "Document and Refer" } \\
\text { (i.e., lists, but does not treat, } \\
\text { most of the ICD codes s/he } \\
\text { lists on claims) }\end{array}$ & $\begin{array}{l}\text { Would appear more } \\
\text { comprehensive than } \\
\text { s/he actually is }\end{array}$ & $\begin{array}{l}\text { Would be able to } \\
\text { distinguish between } \\
\text { more vs. less } \\
\text { comprehensive } \\
\text { clinician }\end{array}$ & $\begin{array}{l}\text { Would appear to be more } \\
\text { comprehensive than } \mathrm{s} / \mathrm{he} \\
\text { truly is }\end{array}$ & $\begin{array}{l}\text { Would not discriminate } \\
\text { well except for } \\
\text { procedures and site } \\
\text { of care }\end{array}$ \\
\hline
\end{tabular}

${ }^{a}$ Range of conditions treated method assesses the range of ICD codes listed on claims by physician for a given time period, e.g., 1 year.

${ }^{b}$ New problems managed refers to the extent to which a patient's new problem is cared for by PCP vs. referred to another specialist.

cInvolvement in patient conditions refers to the clinician's involvement in the care of a patient's conditions relative to other physicians caring for that patient.

${ }^{d}$ Scope of services refers to procedures and interventions done at the practice, including sites of care (inpatient, outpatient, home visits, etc.).

bodies, such as the American Board of Internal Medicine, the American Board of Family Medicine, or the Accreditation Council for Graduate Medical Education, to physician survey and claims-based measures of comprehensiveness. Competing visions of primary care competencies by different generalist disciplines $^{46}$ and an inability to capture from claims some activities outlined by professional associations (e.g., end-oflife planning) might present challenges. ${ }^{80}$ The core services and conditions managed in primary care in other Western industrialized democracies could also inform our consideration of a "gold standard" for comprehensive primary care.

\section{What is the Potential Role of Clinical Information Systems} in Measures of Comprehensiveness? EHR data has potential relevance for several research and future quality measures, including comprehensiveness. Unlike claims data, the EHR can track care delivered outside of face-to-face encounters, although it may be susceptible to some of the same weaknesses as claims data (e.g., the requirement of documentation for feefor-service billing). Studies have used EHR data to identify care processes within and across providers in closed delivery systems and regional health information exchanges. ${ }^{81,82}$ Once more clinically meaningful data (e.g., on referrals, condition management over time, and comorbidities) become routinely collected, standardized and aggregated across providers, EHR data could help to determine which providers are the most comprehensive. In the meantime, the respective strengths, weaknesses and validity of both claims-based and e-measures of comprehensiveness should continue to be assessed.

While most ambulatory care clinicians are still paid on a fee-for-service basis, CMS and other organizations are developing various alternative payment models. As these models still rely on information in fee-for-service claims, this data source will be available for years to come, ${ }^{83}$ but claims may become less informative over time, necessitating greater emphasis on EHR measures.

Other systems for classifying patients and services might also facilitate an understanding of how to support comprehensiveness. The International Classification of Primary Care (ICPC), for example, incorporates not just billing data, but also data on symptoms and reasons for encounters in the patients' own words in addition to provider assessments. ${ }^{84}$ EHR versions of the ICPC are available in Europe, but have been used in only a few institutional EHRs in the U.S. ICPC 
has been cross-walked to ICD-9 and ICD-10. ${ }^{85,86}$ The future iteration, ICPC-3, may provide a structure to link the patient's reason for a clinical encounter with the processes of care and clinician assessment, and then aggregate data across series of encounters to capture care over time. Merging the ICPC-3 with more clinically meaningful EHR data from clinicians has the potential to improve our understanding of the content and comprehensiveness of primary care. ${ }^{84}$

\section{CONCLUSION}

Comprehensiveness is an important aspect of primary care. Developing valid and reliable measures of comprehensiveness could inform quality improvement efforts and help identify providers in need of additional support. Developing an understanding of needs and expectations for comprehensive primary care may also inform efforts to prepare the primary care workforce and shape expectations for maintenance of primary care competencies. If comprehensiveness remains an undermeasured expectation, the current incentives that discourage it may exacerbate its decline.

Acknowledgments: This paper was funded by AHRQ. We are grateful to the technical expert panel for feedback on an earlier version of this manuscript: Robert Reid, Robert Berenson, Robert Phillips, Rebecca Malouin, Scott Shipman and William Hogg. We also thank James E. Ward for his help in editing an earlier version of this manuscript.

Conflict of Interest: The authors declare no conflicts of interest.

Corresponding Author: Ann S. O'Malley, MD, MPH; Mathematica Policy Research, Washington, DC, USA (e-mail: aomalley@mathematicampr.com).

\section{REFERENCES}

1. Starfield B. Primary care: Balancing health needs, services and technology. New York: Oxford University Press; 1998.

2. Agency for Healthcare Research and Quality. About the Patient Centered Medical Home Item Set. Rockville (MD): Agency for Healthcare Research and Quality; 2011. Document \#1314.

3. World Health Organization. Primary health care. Geneva: World Health Organization; 1978.

4. Institute of Medicine. Primary care: America's health in a new era. Washington: National Academy of Sciences; 1996.

5. White KL. Primary medical care for families-organization and evaluation. N Engl J Med. 1967;277:847-52.

6. Lee A, Kiyu A, Milman HM, et al. Improving health and building human capital through an effective primary care system. J Urban Health. 2007;84:i75-i85.

7. Starfield B. State of the art in research on equity in health. J Health Polit Policy Law. 2006;31:11-32.

8. Kringos DS, Boerma WGW, van der Zee J, et al. The contribution of primary care to health care system performance in Europe. In: Kringos DS, ed. The strength of primary care in Europe. Utrecht: Nivel; 2012.

9. Starfield B, Shi L, Macinko J. Contribution of primary care to health systems and health. Milbank Q. 2005;83:457-502.

10. Phillips RL Jr, Bazemore AW. Primary care and why it matters for U.S. health system reform. Health Aff. 2010;29:806-10.

11. Sans-Corrales M, Pujol-Ribera E, Gené-Badia J, et al. Family medicine attributes related to satisfaction, health and costs. Fam Pract. 2006;23:308-16.
12. Wilhelmsson $\mathbf{S}$, Lindberg $\mathbf{M}$. Prevention and health promotion and evidence-based fields of nursing - a literature review. Int J Nurs Pract. 2007; 13:254-65.

13. Chan BTB. The declining comprehensiveness of primary care. CMAJ. 2002; 166:429-434.

14. Safran DG. Defining the future of primary care: what can we learn from patients? Ann Intern Med. 2003;138:248-55.

15. McAlpine DD, Wilson AR. Trends in obesity-related counseling in primary care: 1995-2004. Med Care. 2007;45(4):322-9.

16. Kraschnewski JL, Sciamanna CN, Stuckey HL, Chuang CH, Lehman EB, Hwang KO, Sherwood LL, Nembhard HB. A silent response to the obesity epidemic: decline in US physician weight counseling. Med Care. 2013;51(2):186-92.

17. Barnett ML, Song Z, Landon BE. Trends in physician referrals in the United States, 1999-2009. Arch Intern Med. 2012;172(2):163-70.

18. Starfield B, Chang HY, Lemke KW, Weiner JP. Ambulatory specialist use by nonhospitalized patients in us health plans: correlates and consequences. J Ambul Care Manage. 2009;32(3):216-25.

19. Van de Lisdonk EH, Van Weel C. New referrals, a decreasing phenomenon in 1971-94: analysis of registry data in the Netherlands. BMJ. 1996;313:602.

20. Bindman AB, Forrest CB, Britt $\mathbf{H}$, et al. Diagnostic scope of and exposure to primary care physicians in Australia, New Zealand, and the United States: Cross sectional analysis of results from three national surveys. BMJ. 2007;334:1261.

21. Edwards ST, Mafi JN, Landon BE. Trends and quality of care in outpatient visits to generalist and specialist physicians delivering primary care in the United States, 1997-2010. J Gen Intern Med. 2014;29:947-55.

22. Guevara JP, Hsu D, Forrest CB. Performance measures of the specialty referral process: a systematic review of the literature. BMC Health Serv Res. 2011;11:168.

23. Morra D, Nicholson S, Levinson $\mathbf{W}$, et al. US physician practices versus Canadians: Spending nearly four times as much money interacting with payers. Health Aff. 2011;30(8):1443-50.

24. Shanafelt TD, Boone S, Tan L, et al. Burnout and satisfaction with worklife balance among US physicians relative to the general US population. Arch Intern Med. 2012;172:1377-85.

25. Chen MA, Hollenberg JP, Michelen W, et al. Patient care outside of office visits: a primary care physician time study. J Gen Intern Med. 2011;26:58-63.

26. Rich EC, Lipson D, Libersky J, et al. Organizing care for complex patients in the patient-centered medical home. Ann Fam Med. 2012;10:60-2.

27. Shipman SA, Sinsky CA. Expanding primary care capacity by reducing waste and improving the efficiency of care. Health Aff. 2013;32:1990-7.

28. Berenson RA, Rich EC. US approaches to physician payment: the deconstruction of primary care. J Gen Intern Med. 2010;25:613-8.

29. Russell G, Dahrouge S, Tuna M, et al. Getting it all done. Organizational factors linked with comprehensive primary care. Fam Pract. 2010;27:535-41.

30. Peterson L, Petterson S, Phillips RL, et al. One in fifteen family physicians principally provide emergency or urgent care. JABFM. 2014; 27 [in press].

31. Ratelle JT, Dupras DM, Alguire P, et al. Hospitalist career decisions among internal medicine residents. J Gen Intern Med. 2014;29:1026-30.

32. Pham HH, Grossman JM, Cohen G, et al. Hospitalists and care transitions: the divorce of inpatient and outpatient care. Health Aff. 2008;27:1315-27.

33. Patient centered primary care collaborative. Available at: http://www. pcpcc.org/. Accessed March 13, 2015.

34. American Academy of Family Physicians, American College of Pediatrics, American College of Physicians, et al. Joint Principles of the Patient Centered Medical Home; 2007. Available at: http://www.acponline.org/ running_practice/delivery_and_payment_models/pcmh/demonstrations / jointprinc_05_17.pdf. Accessed March 13, 2015.

35. The National Committee for Quality Assurance. Patient-Centered Medical Home Recognition tool. Available at: http://www.ncqa.org/Programs/Recognition/Practices/PatientCenteredMedicalHomePCMH.aspx. Accessed March 13, 2015.

36. URAC. Patient Centered Medical Home accreditation tool. Available at: https://www.urac.org/accreditation-and-measurement/accreditationprograms/all-programs/patient-centered-medical-home/. Accessed March 13, 2015.

37. The Joint Commission. Primary Care Medical Home Accreditation tool. Available at: http://www.jointcommission.org/accreditation/pchi.aspx. Accessed March 13, 2015.

38. The Accreditation Association for Ambulatory Health Care (AAAHC). Medical Home Accreditation Tool. Available at: http://www.aaahc.org/en/ accreditation/primary-care-medical-home/. Accessed March 13, 2015. 
39. Ginsburg PB, Maxfield M, O'Malley AS, et al. Making medical homes work: Moving from concept to practice; 2008. Available at: http://www. hschange.org/CONTENT/1030. Accessed March 13, 2015.

40. Malouin RA, Starfield B, Sepulveda MJ. Evaluating the tools used to assess the medical home. Manag Care. 2009;18:44-8.

41. Rosenblatt RA, Hart LG, Gamliel S, et al. Identifying primary care disciplines by analyzing the diagnostic content of ambulatory care. J Am Board Fam Pract. 1995;8:34-45.

42. Rayburn WF, Petterson SM, Phillips RL. Trends in family physicians performing deliveries, 2003-2010. Birth. 2014;41:26-32.

43. Perioperative Medicine Summit. Internal Medicine Preoperative Assessment Consultation and Treatment Center; 2010. Available at: http:// periopmedicine.org/2006/06/internal-medicine-preoperative.html. Accessed March 13, 2015.

44. Emory Healthcare. Physicians \& Staff. Available at: http://www emoryhealthcare.org/executive-health/staff.html. Accessed March 13, 2015.

45. Rosenblatt RA, Hart LG, Baldwin LM, et al. The generalist role of specialty physicians: is there a hidden system of primary care? JAMA. 1998;279:1364-70.

46. Rivo ML, Saultz JW, Wartman SA, et al. Defining the generalist physician's training. JAMA. 1994;271:1499-504.

47. Forrest CB, Nutting PA, von Schrader S, et al. Primary care physician specialty referral decision making: patient, physician, and health care system determinants. Med Decis Making. 2006;26:76-85.

48. Mehrotra A, Forrest CB, Lin CY. Dropping the baton: specialty referrals in the United States. Milbank Q. 2011;89:39-68.

49. Valderas JM, Starfield B, Sibbald B, et al. Defining comorbidity: implications for understanding health and health services. Ann Fam Med. 2009;7:357-63.

50. Starfield B, Lemke KW, Herbert R, et al. Comorbidity and the use of primary care and specialist care in the elderly. Ann Fam Med. 2005;3:215-22.

51. Green ME, Hogg W, Savage C, et al. Assessing methods for measurement of clinical outcomes and quality of care in primary care practices. BMC Health Serv Res. 2012;12:214.

52. Starfield B, Cassidy C. Adult Primary Care Assessment Tool. 1998 Available at: http://www.jhsph.edu/research/centers-and-institutes/ johns-hopkins-primary-care-policy-center/pca_tools.html. Accessed March 13, 2015.

53. Safran DG, Kosinski M, Tarlov AR, et al. The Primary Care Assessment Survey: tests of data quality and measurement performance. Med Care. 1998;36:728-39.

54. Safran DG. Ambulatory Care Experiences Survey (ACES); 2004. The Health Institute, New England Medical Center Hospitals Inc.

55. Agency for Healthcare Research and guality. CAHPS $®$ Clinician \& Group Surveys: Overview of the Questionnaires. Rockville (MD): Agency for Healthcare Research and Quality; 2012. Document No. 2350. Available at: https://cahps.ahrq.gov/Surveys-Guidance/CG/index.html. Accessed March 13, 2015

56. Medical Home Implementation Quotient (MHIQ). Available at: http:// www.transformed.com/mhiq/welcome.cfm. Accessed March 13, 2015

57. Strouse R, Potter F, Davis T, et al. 2008 Health tracking physician survey methodology report, technical publication no. 77; September 2009. Available at: http://www.hschange.com/CONTENT/1085/. Accessed March 13, 2015

58. Shortell S, Casalino L. National survey of physician organizations and the management of chronic illness II (medical groups); 2008. Available at: http://nspo.berkeley.edu/NSPOII_MGsurvey-final-pb_20060317_c.pdf. Accessed March 13, 2015.

59. Schäfer WL, Boerma WG, Kringos DS, et al. Measures of quality, costs and equity in primary health care instruments developed to analyse and compare primary care in 35 countries. Qual Prim Care. 2013;21:67-79.

60. DesRoches C, Rich E. Collecting Data on Physicians and Their Practices: Final Report to AHRQ. Washington, DC: Mathematica Policy Research, 2014.

61. Hjortdahl P, Laerum E. Continuity of care in general practice: effect on patient satisfaction. BMJ. 1992;304:1287-90.

62. Kao AC, Green DC, Davis NA, et al. Patients' trust in their physicians: effects of choice, continuity, and payment method. J Gen Intern Med. 1998; 13:681-6.

63. Fisher ES, Wennberg DE, Stukel TA, et al. The implications of regional variations in Medicare spending. Part 1: the content, quality, and accessibility of care. Ann Intern Med. 2003;138:273-87.

64. Wennberg JE. Practice variations and health care reform: connecting the dots. Health Aff. 2004;Suppl Variation:VAR140-4.
65. Haggerty JL, Beaulieu MD, Pineault R, Burge F, Levesque JF, Santor DA, Bouharaoui F, Beaulieu C. Comprehensiveness of care from the patient perspective: comparison of primary healthcare evaluation instruments. Health Policy. 2011;7(Spec Issue 1):54-66.

66. Centers for Disease Control and Prevention. National Ambulatory Care Medical Survey (NAMCS): 2010 summary tables. Available at: http://www. cdc.gov/nchs/data/ahcd/namcs_summary/2010_namcs_web_tables.pdf. Accessed December 4, 2014.

67. Schneeweiss R, Rosenblatt RA, Cherkin DC, et al. Diagnosis clusters: a new tool for analyzing the content of ambulatory medical care. Med Care. 1983;21:105-22.

68. Hammermeister K, Bronsert M, Henderson WG, et al. Risk-adjusted comparison of blood pressure and low-density lipoprotein (LDL) noncontrol in primary care offices. J Am Board Fam Med. 2013;26:658-68.

69. Pace WD, Dickinson LM, Staton EW. Seasonal variation in diagnoses and visits to family physicians. Ann Fam Med. 2004;2:411-7.

70. Franks P, Clancy CM, Nutting PA. Defining primary care. Empirical analysis of the National Ambulatory Medical Care Survey. Med Care. 1997;35(7):655-68.

71. Steindel SJ. International classification of diseases, 10th edition, clinical modification and procedure coding system: descriptive overview of the next generation HIPAA code sets. J Am Med Inform Assoc. 2010;17:274-82.

72. Petterson S, Bazemore A, Phillip R, et al. Broader scope of practice and comprehensiveness is associated with lower health care costs. Academy Health; 2014 Jun 8-10; San Diego. Available at: http://www. academyhealth.org/Events/content.cfm?ItemNumber=13256. Accessed March 13, 2015.

73. The Johns Hopkins Adjusted Clinical Groups $\mathrm{ACG}^{\odot}$ System. About the ACG system. Available at: http://acg.jhsph.org/. Accessed March 13, 2015.

74. Centers for Medicare and Medicaid Services. Berenson-Eggers Type of Service (BETOS). Available at: http://www.cms.gov/Medicare/Coding/ HCPCSReleaseCodeSets/BETOS.html. Accessed March 13, 2015.

75. Woolhandler S, Himmelstein DU. Savings from the Medicare Physician Group Practice Demonstration. JAMA. 2013;309:30-1.

76. Nelson L. Lessons from Medicare's demonstration projects on value-based payment. Washington, D.C.: Congressional Budget Office; 2012. Working Paper 2012-01. Available at: http://www.cbo.gov/sites/default/files/ cbofiles/attachments/WP2012-01_Nelson_Medicare_DMCC_Demonstrations.pdf. Accessed March 13, 2015.

77. Medicare Payment Advisory Commission (MedPAC). Report to the Congress: Medicare Payment Policy. March 2014. Available at: http:// www.medpac.gov/documents/reports/mar14_entirereport.pdf?sfvrsn=0. Accessed March 13, 2015.

78. National Quality Measures Clearinghouse. Measure summary: Use of imaging studies for low back pain: Percentage of members with a primary diagnosis of low back pain who did not have an imaging study (plain x-ray, MRI, CT scan) within 28 days of the diagnosis. http://www.guideline.gov/ content.aspx?id=34670. Accessed March 13, 2015.

79. Weiner JP, Parente ST, Garnick DW, et al. Variation in office-based quality. A claims-based profile of care provided to Medicare patients with diabetes. JAMA. 1995;273:1503-8.

80. Williams BC, Warshaw G, Fabiny AR, et al. Medicine in the 21 st century: recommended essential geriatrics competencies for internal medicine and family medicine residents. J Grad Med Educ. 2010;2:373-83.

81. Lammers EJ, Adler-Milstein J, Kocher KE. Does health information exchange reduce redundant imaging? Evidence from emergency departments. Med Care. 2014;52:227-34.

82. Tai-Seale M, Wilson CJ, Panattoni L, et al. Leveraging electronic health records to develop measurements for processes of care. Health Serv Res. 2014;49:628-44.

83. Reschovsky JD, Converse L, Rich EC. Solving the Sustainable Growth Rate Formula Conundrum Continues Steps Toward Cost Savings and Care Improvement. Health Affairs, Web First, 2015, in press.

84. World Organization of National Colleges, Academies and Academic Associations of General Practitioners/Family Physicians (WONCA). WONCA Working Party: WICC (International Classification). Available at: http://www.globalfamilydoctor.com/groups/WorkingParties/wicc.aspx. Accessed March 13, 2015.

85. Verbeke M, Schrans D, Deroose S, et al. The International Classification of Primary Care (ICPC-2): an essential tool in the EPR of the GP. Stud Health Technol Inform. 2006;124:809-14.

86. Soler JK, Okkes I, Wood M, et al. The coming of age of ICPC: celebrating the 21st birthday of the International Classification of Primary Care. Fam Pract. 2008;25:312-7. 